\title{
The Design of a Wideband Microstrip Marchand Balun
}

$$
\text { Yan Pu }{ }^{a} \text {, Xun Luo }{ }^{b} \text {, Wei Zou }{ }^{c} \text { and Guoqiang Wang }{ }^{d}
$$

Analog IC Design Department, Sichuan Institute of Solid-state Circuits, Chongqing 400060, China.

apuyan_2012@163.com, bluoxun2008@126.com, czouwei19861105@163.com,

dwgq198202@aliyun.com

\begin{abstract}
A miniaturized wideband microstrip Marchand balun is presented in the paper. The balun is simulated and optimized in ADS and HFSS to evaluate the characterization. The Balun is fabricaded on a double-sided PCB by Rogers's 5880 material. The results show that, the bandwidth of the balun is from $8 \mathrm{GHz}$ to $16 \mathrm{GHz}$. The insert loss is within $5 \mathrm{~dB}$, and the return loss of the three ports is better than $-5 \mathrm{~dB}$ in the bandwidth. The measured amplitude imbalance and phase difference between the two balanced output ports are within $1 \mathrm{~dB}$ and $10^{\circ}$ over the whole frequency band.
\end{abstract}

Keywords: Marchand Balun; Wideband; ADS; HFSS.

\section{Introduction}

With the explosive growth in the wireless communication industry, wideband transceivers have gained significant popularity during the past two decades, and they provide the flexibility of operation at various frequencies simultaneously $[1,2]$. As the differential signal is widely used to get rid of the noise and high order harmonics, many circuits require balanced inputs and outputs connections in the common used transceiver systems [3].

Baluns are widely used in almost all RF front-end wireless communication systems, such as double balanced mixers, push-pull amplifiers, frequency doublers and antenna feed networks [4, 5, 6, 7].They can help to improve the dynamic range of the circuits and achieve higher stability against non-ideal grounding. A properly designed balun plays a key role in some types of circuit. In fact, it is sometimes the performance of the balun which predominately determines the performance of the whole systems.

As a kind of distributed passive Baluns, Marchand Balun becomes very popular in microwave frequency applications because of its ease of implementation and wide bandwidth [8]. In this paper, simple theory and design procedure are presented to optimize the miniatured microstrip Marchand balun. The balun is first simulated by ADS. The proposed new structure is then simulated by the full-wave electromagnetic software Ansys HFSS and validated by the measurement, finally.

\section{The Structure of Marchand Balun}

Marchand balun was raised by Nathan Marchand in 1944 [9]. The equivalent circuit is showed in Fig.1, and the balun consists of two identical sections of coupling lines, which are $\lambda / 4$ long at the center of operating frequency. Port 1 is the unbalanced input port with $\lambda / 2$ transmission line long to the other open-circuit terminal, and Port 2 and Port 3 are balanced output ports with $\lambda / 4$ transmission lines long to the two short-circuit terminals respectively. The unbalanced signal from input port to output ports passes through $\lambda / 4$ and $3 \lambda / 4$ respectively, and the phase difference between the two output signals is 180 degree.

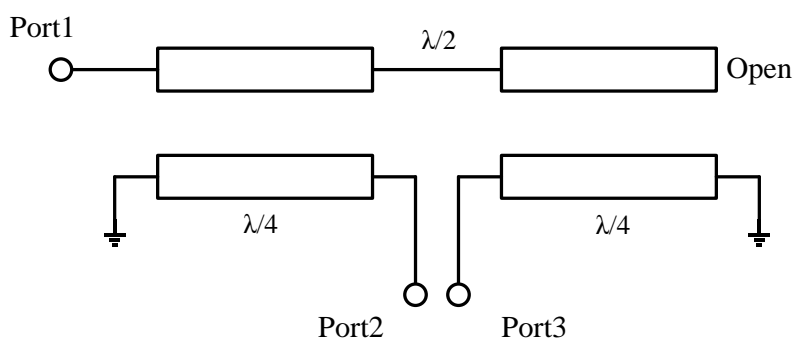

Fig. 1 The Marchand Balun structure 
The Marchand balun can be easily realized by microstrip line or stripline. To achieve better balance property, a strong coupling is required for both the two coupled line sections, and symmetry should also be taken into account. The microstrip coupled lines are used in the proposed Marchand balun structure, and the schematic of the balun in ADS is shown in Fig.2. The initial parameters can be obtained in virtue of the optimization function, and they will be used to construct the 3D physical model in full-wave 3D EM simulator HFSS [10], which is more likely closer to the actual reality.

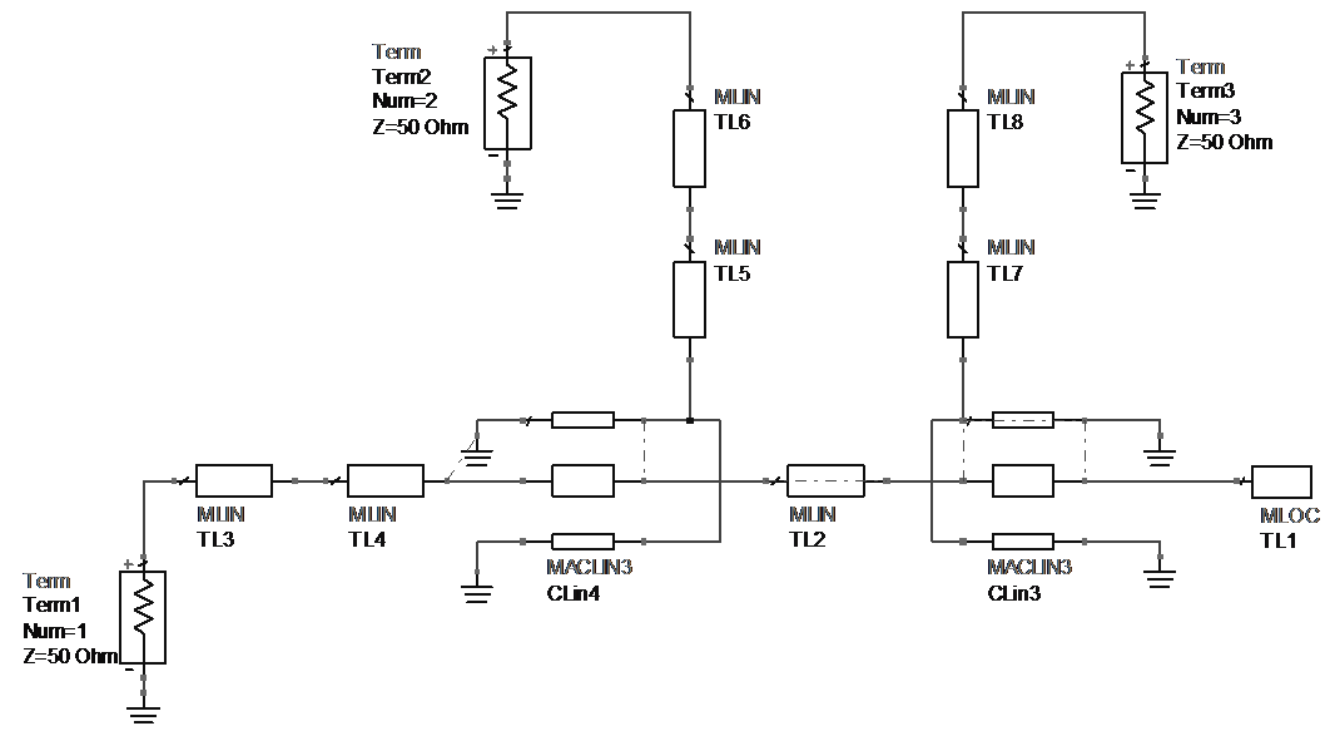

Fig. 2 The schematic of the Marchand balun in ADS

For the design and measurement convenience, the impedances in all the balanced and unbalanced ports are assumed to be $50 \Omega$. Figure 3 shows the simulation results of the balun in ADS, which can be used to evaluate the performance of the balun. The bandwidth of the simulation results is from $9 \mathrm{GHz}$ to $19 \mathrm{GHz}$. The return loss of the unbalanced port is below $-10 \mathrm{~dB}$, and the return loss of the balanced ports is about $-5 \mathrm{~dB}$. The basic performance of the Marchand balun can be evaluated from the simulation results in ADS, which can be used to optimize the physical dimensions of the 3D structure in Ansys HFSS for EM simulation.
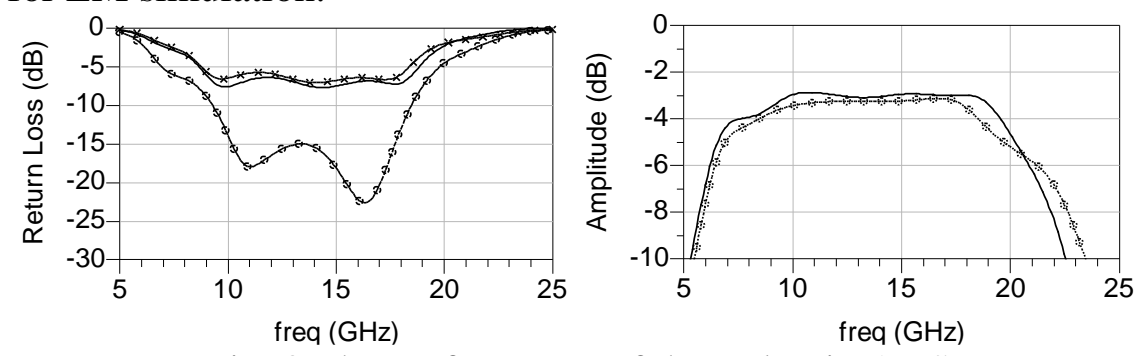

Fig. 3 The performance of the Balun in ADS

\section{Simulation and Results}

In order to gain the 3D EM simulation results of the balun structure, Ansys HFSS is employed to analyze the coupled microstrip line structure. The Marchand balun on a double-sided PCB is designed, simulated, fabricated and measured. The physical 3D view of the Marchand Balun is shown in Fig.4. The microstrip connected with the unbalanced port is bended to achieve a miniature structure. It is established by a double-sided PCB technology with the specific material parameters as listed: the relative permittivity of Rogers's material is 2.2 with the thickness of $0.254 \mathrm{~mm}$. The metal conductor is gold and its thickness is about $18 \mu \mathrm{m}$. The surface gold geometry of the Rogers material is the Marchand Balun, the backside of the material is all ground. The vias are used to connect the ground between the front side and the back side. The bondwires are used to connect the microstrip lines as shown in the picture. 


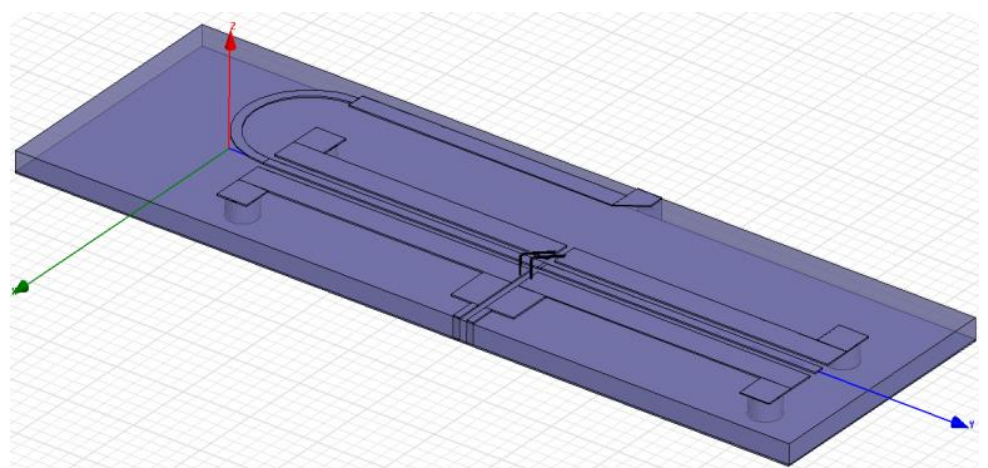

Fig. 4 The 3D schematic view of the Marchand Balun structure in HFSS

The lumped ports are used to excite the three ports of the geometric model. The optimization is performed to get the best performance of the balun in the HFSS, and the initial values are parameters simulated in the ADS before. The coupling effects between the microstrip lines, the horizontal space, vertical gap, vias and bondwires etc in the 3D geometry can be simulated accurately in the HFSS EM simulator. The fabricated Marchand balun on Rogers material is shown in Fig. 5. The ports are all connected with a section of $50 \Omega$ microstrip line for measurement convenience.

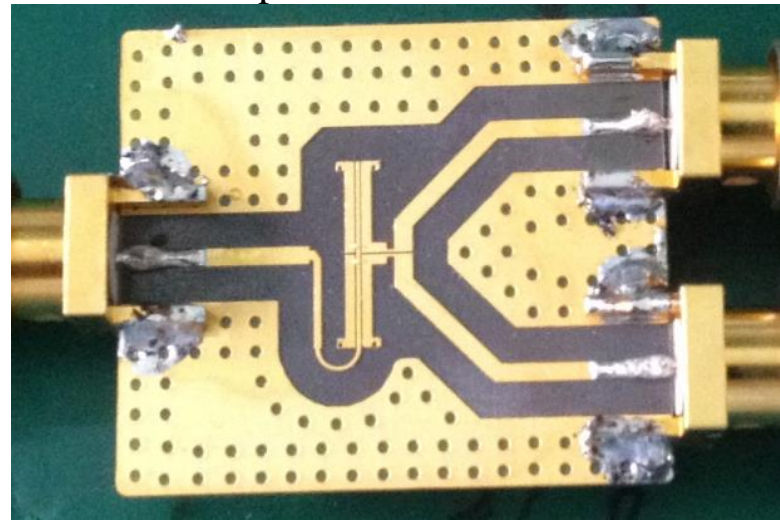

Fig. 5 The photo of the fabricated Marchand balun

The measurement was carried out on an N5242A vector network analyzer. As a wideband three-port lossless network, the Marchand baluns cannot be matched simultaneously at all ports, as shown in Fig. 6, the return loss of the balanced ports is below $-5 \mathrm{~dB}$, and the return loss of the unbalanced port is below $-10 \mathrm{~dB}$. The insertion loss of the simulation is less than $4 \mathrm{~dB}$ from $8 \mathrm{GHz}$ to $18 \mathrm{GHz}$, while the one of measurment is less than $5 \mathrm{~dB}$ from $7 \mathrm{GHz}$ to $17 \mathrm{GHz}$, as shown in Fig. 7.

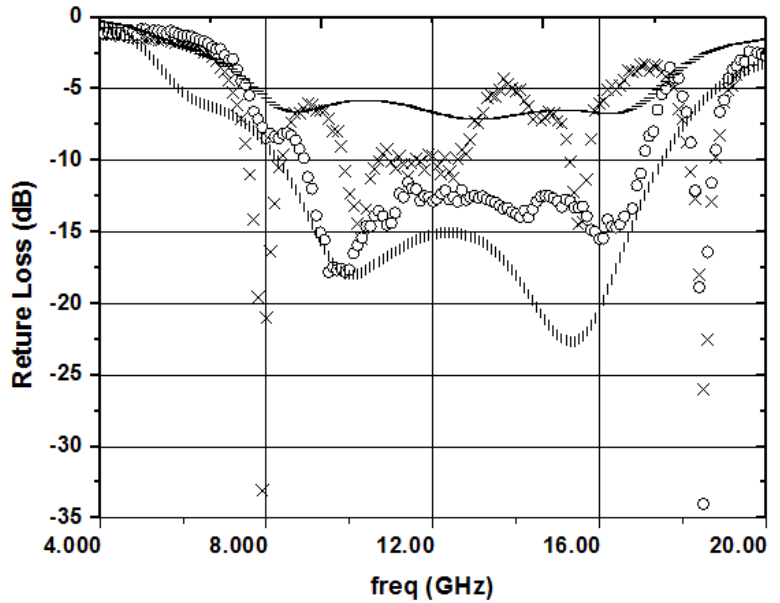

Fig. 6 The return loss between the simulated results of HFSS (the symbol "-" is port2 and the sybmol "|" is port1) and the measurement (the symbol "x" is port2 and the sybmol "o" is port1) 


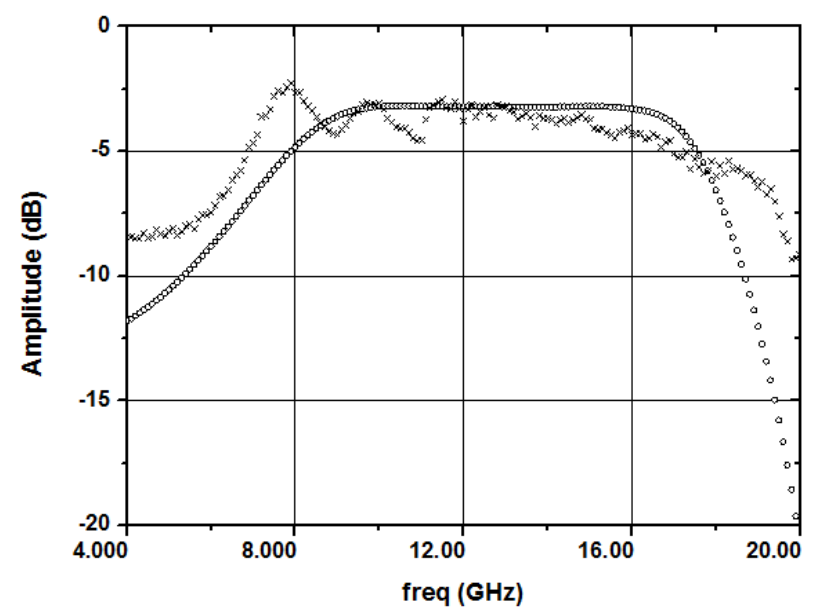

Fig. 7 The insertion loss between the simulated results of HFSS (the symbol "o" ) and the measurement (the symbol "x" )

In Figs. 8, it is shown that the simulated and measured results of the amplitude imbalance and phase difference about the microstip Marchand balun. The amplitude imbalance between port2 and port 3 is less than $1 \mathrm{~dB}$, and the phase difference between the two ports is less than $10^{\circ}$.

Compared to the simulated results, the frequency range of the banlun in measured ones is a little shifted to the lower frequency. On one side, the discrepancies between simulation and measurement may mainly come from the fabrication tolerances, on the other side, the influence of parasitic parameters and the environment can also be accounted for the difference. It can be obtained very good agreement if the whole structure is fabricated in a closed cavity. To some extent, the measured results agree well with the simulated ones, the simulation results of the HFSS can give the best predictions of the PCB fabrication sturcture.
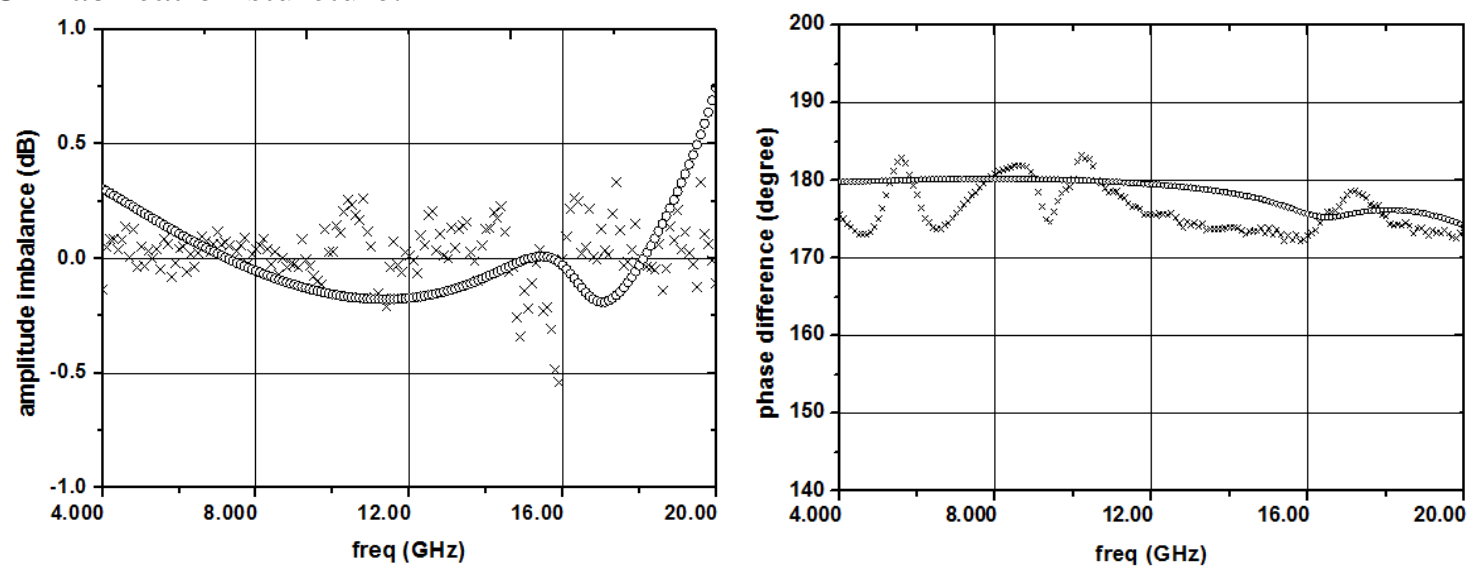

Fig. 8 The amplitude imbalance and phase difference between the simulated results of HFSS (the symbol "o") and the measurement (the symbol "x")

A wideband Marchand balun was designed and simulated by the full-wave 3D electromagnetic software HFSS. It was fabricated in Rogers 5880 doubled-sided PCB material. The measurement results show that the balun achieves low insertion loss and good balance in the frequency band from 6 $\mathrm{GHz}$ to $16 \mathrm{GHz}$. It is proved that Ansys HFSS can give the best performance predictions in the 3D microstrip structure.

\section{Summary}

A miniaturized microstrip Marchand balun fabricated on the Rogers 5880 substrate was designed in the paper. The design was simulated by the full-wave electromagnetic software Ansys HFSS and verified by the measurement. The insertion loss of the balun is about $-5 \mathrm{~dB}$ around the frequency band, and the measured amplitude imbalance and phase difference between the two balanced ports are within $1 \mathrm{~dB}$ and $10^{\circ}$ in the operating frequency band. A reasonably good agreement has been achieved between the simulation and measurement results. 


\section{References}

[1] H Zheng, SZ Lou, L Leung, HC Luong, RF system architectures and circuit techniques for wideband transceivers, IEEE International Workshop on Radio - Frequency Integration Technology: Integrated Circuits for Wideband Communication and Wireless Sensor Networks, 2005. Proceedings. (2005) 30 - 37.

[2] D Yang, H Yuksel, A Molnar, A wideband highly integrated and widely tunable transceiver for in-band full - duplex communication, IEEE Journal of Solid-State Circuits. 50.5 (2015) 1189-1202.

[3] B Godara, A Fabre, B Godara, A Fabre, State of the Art for Differential Circuits in Wireless Transceivers: A New Wideband Active Balun in SiGe BiCMOS Technology, Turkish Journal of Electrical Engineering \& Computer Sciences. 14.3 (2007) 355-386.

[4] ZP Li, X Dai, LT Wei, JW Sun, JX Liu, Design of a Ka - band double balance mixer based on the marchand balun, Electronic Measurement \& Instruments (ICEMI), 2015 12th IEEE International Conference. IEEE. 2(2015) 939-942.

[5] J Zhou, K Morris, G Watkins, K Yamaguchi, Three - band high - efficiency modulator for envelope tracking power amplifier using class-B push-pull amplifiers, Microwave Conference (EuMC), 2012 42nd European. IEEE. 8273(2012) 124-127.

[6] PH Tsai, YH Lin, JL Kuo, ZM Tsai, H Wang, Broadband balanced frequency doublers with fundamental rejection enhancement using a novel compensated Marchand balun, IEEE Transactions on Microwave Theory and Techniques. 61.5 (2013) 1913-1923.

[7] I Piekarz, J Sorocki, K Wincza, S Gruszczynski, Wideband Marchand balun and bow-tie antenna for sensor aplications, 2015 International Symposium on Antennas and Propagation (ISAP). IEEE. (2015) 1-3.

[8] JX Xu, XY Zhang, XL Zhao, Compact LTCC Balun With Bandpass Response Based on Marchand Balun, IEEE Microwave and Wireless Components Letters. 26.7 (2016) 493-495.

[9] N. Marchand, Transmission-line conversion transformers, Electronics. 17 (1944) 142-145.

[10] SAP Rizvi, RAA Khan, Klopfenstein tapered 2-18 GHz microstrip balun, Proceedings of 2012 9th International Bhurban Conference on Applied Sciences \& Technology (IBCAST). IEEE. (2012) 359-362. 